\title{
A TERCEIRIZAÇÃO DEBATIDA NO PARLAMENTO BRASILEIRO ANTE A EXPERIÊNCIA JURÍDICA NACIONAL E ESTRANGEIRA: O ESTADO E A TUTELA DO TRABALHO DURANTE CRISES ECONÔMICAS
}

\author{
OUTSOURCING DEBATED IN BRAZILIAN PARLIAMENT \\ CONSIDERING THE NATIONAL AND FOREIGN LEGAL EXPERIENCE: \\ THE STATE AND THE WORK PROTECTION DURING ECONOMIC \\ CRISES
}

\author{
Renato de Almeida Oliveira Muçouçah \\ Universidade Federal do Rio de Janeiro (UFRJ) - (Rio de Janeiro, RJ, Brasil)
}

Recebimento: 20 mar. 2017

Aceitação: 10 jun. 2017

\begin{abstract}
Como citar este artigo / How to cite this article (informe a data atual de acesso / inform the current date of access):
MUÇOUÇAH, Renato de Almeida Oliveira. A terceirização debatida no parlamento brasileiro ante a experiência jurídica nacional e estrangeira: o Estado e a tutela do trabalho durante crises econômicas. Revista da Faculdade de Direito UFPR, Curitiba, PR, Brasil, v. 62, n. 2, p. 149 - 174, maio/ago. 2017. ISSN 2236-7284. Disponível em: <http://revistas.ufpr.br/direito/article/view/51316>. Acesso $\quad$ em: 28 ago. $2017 . \quad$ DOI:
\end{abstract} http://dx.doi.org/10.5380/rfdufpr.v62i2.51316.

\section{RESUMO}

Este estudo tem como objetivo analisar as discussões existentes no parlamento brasileiro acerca da regulamentação legal do fenômeno da terceirização. Há breve análise acerca do contexto em que se insere a terceirização no Brasil, economia capitalista de alta competitividade, que enfrenta crises financeiras e altos índices de desemprego. Com o auxílio da experiência jurídica estrangeira (notadamente europeia), busca-se verificar as respostas obtidas pelos países com as legislações adotadas: em muitos casos, constata-se que houve afronta a postulados básicos da dogmática jurídica trabalhista e o Estado de bem-estar social restou enfraquecido. Questiona-se, ademais, a produção e interpretação de normas jurídicas em tempos de crise, bem como o impacto de tais preceitos quanto a postulados constitucionais e trabalhistas. Para tanto, buscou-se o estudo hipotético-dedutivo das questões existentes nas lacunas do direito brasileiro, via análise dedutiva de bibliografia nacional e estrangeira especializadas na temática, e as hipóteses de resposta por elas apresentadas. O enfrentamento de crises econômicas, com o aval do Poder Judiciário, por meio de legislação criada para amenizá-las, avilta direitos fundamentais de natureza social, incluindo direitos individuais do trabalhador. E, ao contrário das crises, tais alterações são perenes e enfraquecem o Estado de bemestar social, gerando retrocesso social, como observado em todas as experiências jurídicas estrangeiras já analisadas. Embora haja tentativas de retorno a um novo conceito de liberalismo econômico, a defesa constitucional não permite a reversão de conquistas já alcançadas, não permitindo assim que se legisle, em momentos de crise econômica ou desemprego, sobre retirada de direitos fundamentais do trabalhador.

\section{PALAVRAS-CHAVE}

Terceirização. Proibição do retrocesso social. Direitos fundamentais sociais. Enfraquecimento sindical. Desemprego. 


\begin{abstract}
This study analyzes the discussions in the Brazilian parliament about the legal regulation of the outsourcing phenomenon. There is an analysis about the context of outsourcing in Brazil, a competitive capitalist economy, which is facing a financial crisis and high unemployment rates. Based on foreign legal experience (notably European), it seeks to verify the responses obtained by the countries which have adopted legislation about outsourcing: In many cases an affront to basic postulates of labor legal dogmatic, and a weakening of the welfare state, have been verified. The production and interpretation of legal norms in times of crisis were also questioned, as well as the impact of such precepts on constitutional and labor postulates. For this purpose, a hypotheticaldeductive study of the Brazilian law gaps issues was sought, through a deductive analysis of national and foreign bibliography specialized in the subject and the hypotheses of response presented by them. Confronting an economic crisis through a legislation designed to ease economic crises, with the approval of the Judiciary, detracts fundamental social rights, including worker's individual rights. Contrary to crises, besides, such changes are perennial and weaken the welfare state, generating social regression, as observed in all foreign legal experiences already analyzed. Although there are attempts to return to a new concept of economic liberalism, constitutional defense does not allow the reversal of attainments already achieved, thus not allowing legislation that seeks to withdrawal workers' fundamental rights in case of economic crises or unemployment.
\end{abstract}

\title{
KEYWORDS
}

Outsourcing. Prohibition of social regression. Fundamental social rights. Union weakening. Unemployment.

\section{INTRODUÇÃO}

Não é incomum, em momentos de crise do capitalismo global, que medidas legislativas sejam tomadas pelos Estados para enfrentá-la. Em momentos de depressão econômica, todos os atores sociais - especialmente na concepção tripartite oferecida pela Organização Internacional do Trabalho (Estado, empregados e empregadores) - buscam medidas que atenuem o desemprego, como acordos e convenções coletivas que temporariamente diminuam salários e correspondente jornada de trabalho, férias coletivas e outras soluções possibilitadas, em grande medida, pelo modelo negocial trazido pela Constituição Federal em seus artigos $7^{\circ}$ a 11.

Também não é incomum que o parlamento, constituído por representantes do povo e dos estados-membros, proponham, por meio de lei, medidas de combate ao desemprego durante as crises econômicas. A terceirização, à larga praticada no Brasil, surge nos debates como possível alternativa à criação de postos de trabalho.

Esse modelo de relação trilateral de emprego, cuja fórmula rompe com paradigmas clássicos do direito trabalhista, apresentou-se como verdadeiro fenômeno social: na inexistência de normas que expressamente proibissem tal prática, foi ela, valendo-se de lacunas do ordenamento jurídico, adotada por empresas dos mais diversos setores da economia e até mesmo pela administração pública, até que 
restou balizada pela Súmula 331 do Tribunal Superior do Trabalho (TST). Somente em 31 de março de 2017, por meio da Lei 13.429, o Brasil adotou legislação específica e global acerca da terceirização, ao contrário de diplomas mais antigos, que previam a possibilidade de terceirização em setores específicos de trabalho (como no caso dos vigilantes bancários - Lei 7.102, de 20 de junho de 1983).

O Estado de bem-estar social iniciado nos primórdios do século XX, o qual se tornou regra no mundo do pós-Guerra, reflete-se claramente no Brasil diante da leitura da Constituição Federal de 1988. Trata-se de concepção que busca intervir na economia para proteção do trabalho, incentivo à produção industrial, criação de infraestrutura para impulsionar o desenvolvimento econômico-social, etc. Embora cada nação tenha peculiaridades próprias, a globalização da economia, do capital e de suas crises engendram práticas semelhantes de enfrentamento, o que pode ser atestado com o fenômeno da terceirização.

Países europeus com tradição jurídica bastante similar à brasileira buscaram, nos últimos quinze anos, regulamentar a terceirização e, ao mesmo tempo, manter garantias mínimas de direitos sociais aos trabalhadores terceirizados; em virtude disso, a experiência jurídica desses Estados pode orientar as discussões acadêmicas e também a legislativa, ainda em curso no Brasil.

O parlamento brasileiro tem discutido, com bastante ênfase, fórmulas para regulamentar a terceirização: a Câmara dos Deputados, após debates acerca do tema, aprovou texto que remeteu à análise do Senado. Trata-se do Projeto de Lei da Câmara (PLC) 30/2015. Com o objetivo de alterar certas regras atinentes ao fenômeno citado, apresentou-se o Projeto de Lei do Senado (PLS) 339/2016, como substitutivo ao texto aprovado na câmara baixa, no afã de tornar mais rígidas certas regras existentes no texto inicial.

Numa espécie de malabarismo regimental a Câmara dos Deputados votou, em março de 2017, Projeto de Lei de Terceirização (PL 4.302/98) proposto há quase vinte anos, sem que ele seguisse para nova discussão na câmara alta - uma vez que tal projeto, no Senado, havia sido aprovado também há quase vinte anos. As discussões iniciais, ocorridas entre o final do primeiro e o início do segundo mandato do governo Fernando Henrique Cardoso (1995-2002), tramitavam em passos lentos ou, por assim dizer, restavam praticamente arquivadas. A partir de 2017, contudo, em pouco mais de um mês o governo fez ressurgir tal projeto e o colocou na pauta do dia, resultando na promulgação da Lei 13.429, de 31 de março do mesmo ano, que veio mistificar e confundir ainda mais a discussão sobre o tema no Brasil.

O presente artigo objetiva discutir o fenômeno da terceirização brasileira e a forma como vêm sendo discutidas as normas que tentam regulamentar tal prática, com a análise de outras 
experiências jurídicas, as quais a regulamentaram em outros quadrantes do mundo. Questiona-se, ademais, o papel da terceirização como fórmula de combate ao desemprego e a viabilidade - ou não - de discuti-la em tempos de depressão econômica. O principal questionamento a ser enfrentado, pois, refere-se ao Estado de bem-estar social: as fórmulas debatidas no parlamento podem significar ou não o enfraquecimento dessa concepção de Estado e, nesse sentido, é inevitável perquirir o que a experiência jurídica de outros países recomenda em relação à atividade em comento.

Por ser tema cujo estudo demanda conhecimentos de direito do trabalho e, em certa medida, direito constitucional, perpassando a discussão por outras searas do conhecimento, o tratamento dedutivo da pesquisa bibliográfica analisará obras jurídicas e sociológicas acerca do tema proposto, tanto nacionais quanto estrangeiras. Buscar-se-á, por meio de teste dedutivo de hipóteses (método hipotético-dedutivo), apresentar respostas quanto às lacunas encontradas nos estudos, máxime no que diga respeito à amplitude do possível retrocesso social trazido aos trabalhadores e ao Estadoprovidência.

\section{A TERCEIRIZAÇÃO CONTEMPORÂNEA}

O desemprego e a informalidade podem ser considerados os mais acintosos ataques ao valor social do trabalho e à dignidade social do homem, já que, no primeiro caso, não há sequer exercício de uma atividade produtiva: o desenvolvimento dessa importante faceta da subjetividade humana resta ceifado ${ }^{1}$. Aponta-se também que ambas as situações criam um círculo vicioso em relação à mantença dessa situação de exclusão e depreciação do trabalhador, pois aquele que está desempregado ou trabalha informalmente não empresta sua força política pessoal e coletiva para que seus pares busquem melhoria de suas condições de vida.

O fenômeno descrito como terceirização, adiante explicitado, embora se relacione com informalidade e desemprego, foi (e ainda é) a promessa de emprego em diversas sociedades. Tenta qualificar-se como antítese dos dois fenômenos descritos.

Como bem salienta Florestan Fernandes (2005, p. 179-233), o capitalismo molda a sociedade em que é adotado como regime econômico, de maneira a criar uma ordem social competitiva. Em países como o Brasil, que ainda eram regidos pelo sistema colonial, o regime capitalista acaba por ser determinado antes da formação de uma ordem competitiva, de maneira tal que revoluções políticas

\footnotetext{
${ }^{1}$ Agregando análise psicológica quanto ao desempenho, ou não, do trabalho, e toda a representatividade social e subjetiva que isto envolve, “o trabalho, na visão preponderante, é um dever. Trabalhar é condição sine qua non para viver. Não o é, apenas, para viver materialmente, mas para que alguém seja socialmente confiável. Ser confiável é ter o testemunho de outro que lhe atribui existência social” (SATO; SCHMIDT, 2004, p. 366-367).
} 
(como a independência do País) não significaram, também, rupturas econômicas. Por isso mesmo, é falso o argumento no sentido de que a legislação trabalhista busca paz social: trata-se apenas de um discurso retórico do patronato.

É com a revolução burguesa que surge uma reflexão paradoxal: o homem é um produto do meio social, mas, ao mesmo tempo, o meio social é criado por opiniões e posições políticas partilhadas. Na sociedade do capital é que os problemas do ser social transcendem a figura individual do homem: esta sociedade se encontra "feita" diante do homem, tal como o mundo da natureza e, portanto, é preciso desbravá-la e dela retirar o que for possível. O homem se torna objeto, e não mais sujeito do processo social (LUKÁCS, 2012, p. 282-293).

Nesse contexto processa-se o fenômeno da globalização econômico-financeira, a qual, como bem salientam Gérard Duménil e Dominique Lévy (2014, p. 71-90), pulverizam as relações mediante conceitos próprios de hierarquia. Nessas relações, as multinacionais e os grandes conglomerados econômicos encontram-se no topo e, na base, é possível observar as pequenas e médias empresas. Sejam os detentores do capital grandes, médios ou pequenos empreendedores, a forma pela qual o trabalho humano é explorado não se diferencia muito, a depender do porte da empresa que o emprega; observa-se com maior frequência, aliás, a submissão de médias e pequenas empresas ao sistema financeiro o qual, certamente, não defende interesses da classe trabalhadora.

Os novos papéis da classe que vive de seu trabalho modificaram-se nesse ciclo financeiro do capital. Graças às novas tecnologias, diversos postos de trabalho foram ceifados, e cada vez se encontram menos oportunidades de trabalho. Para a classe proletária sobreviver, portanto, acaba por aceitar qualquer forma de labor. Essa nova tipologia segue a lógica dos "novos modos de ser do proletariado” (ANTUNES, 2011, p. 104, grifo do autor).

O deslocamento da produção, de certa maneira, “desnacionaliza” os sistemas jurídicos trabalhistas com justificativa em um tripé: flexibilidade da legislação, a fim de que o empregador tenha o mínimo possível de deveres; competitividade, que se firma por meio de baixos salários pagos pelo capital aos empregados que, temerosos quanto à possibilidade de desemprego ou ao encaminhamento à marginalidade do sistema justrabalhista, representado pela informalidade, submetem-se a qualquer tipo de trabalho, seja qual for a remuneração percebida; e, por fim, a desregulamentação de direitos trabalhistas, devendo o acordo entre as partes sempre prevalecer sobre o que é legislado (PURCALLA BONILLA, 2009, p. 51-53).

Conceituando-se o fenômeno da terceirização de maneira bastante simples, pode-se notar que ele busca a existência de uma empresa enxuta (ou mínima): parte das atividades de trabalho da empresa é repassada a prestadores de serviço, que são terceiros em relação às figuras do empregado 
e do empregador. Tais contratos não têm natureza trabalhista, mas sim, na maior parte das vezes, regramentos típicos do direito comum (civil). A empresa, valendo-se dessa estratégia, busca focar apenas o núcleo duro de seu objeto, valendo-se da mão de obra do menor número possível de empregados.

Essa forma trilateral de prestação de serviços não altera as tensões entre capital e trabalho; parecem, ao revés, torná-las ainda mais densamente visíveis. Robert Castel (1998, p. 415-436) demonstra uma série de mudanças no sistema capitalista: inicialmente, havia duas formas possíveis de integração do capital ao trabalho. A primeira delas, “condição proletária”, inseria, sem direito algum, seres humanos no meio produtivo. Os trabalhadores buscavam trabalhar apenas para reproduzirem-se materialmente e se alimentar. A fase posterior, denominada como de "condição operária”, marca o nascimento do Estado social.

O fenômeno do chamado Estado-providência é bem explorado por François Ewald: a sociedade industrial trouxe um problema - o da "condição proletária" - que desafia até mesmo os postulados liberais. Conforme o autor, foram os acidentes do trabalho e a necessidade de sistemas de seguridade social que modificaram o status quo do pensamento jurídico ainda liberal. Para o pagamento de invalidezes temporárias ou permanentes seria necessário responsabilizar alguém. A solução para esse problema foi, inicialmente, a ideia de socialização de riscos, promovida pelo Estado por meio de algum instituto financiado pelos cofres públicos e pelos particulares, como a questão da invalidez e da velhice (EWALD, 1986, p. 85-90).

Hoje, conforme o citado Castel, vive-se na sociedade salarial: a regra é a de que os seres humanos, em sua maioria, vivem somente por meio de algum tipo de remuneração, seja oriunda do trabalho subordinado, do autônomo ou de novas formas de conquista de dinheiro por meio do labor. Se durante os primórdios do liberalismo a tese de que trabalhadores e tomadores de serviços eram iguais numa relação jurídica, o Estado-providência buscou legislar em sentido contrário, objetivando proibir o aviltamento da dignidade social da pessoa que vive apenas de seu trabalho.

Atualmente, logo após a adoção desse processo de transformar empresas em termos que denominam “enxutas” (menor número possível de empregados, com máxima produtividade), o discurso liberal da produção flexível, que poderia gerar mais postos de trabalho e tornar a empresa mais competitiva no mercado, parece ter ressuscitado a “condição proletária”: a flexibilização das relações de trabalho busca frisar, discreta e paulatinamente, que o tomador da força de trabalho é um contratante em condições cada vez mais semelhantes às de quem lhe presta serviços.

Esse novo liberalismo marca o início da tentativa de desmonte do Estado-providência: tratase, pois, de um retrocesso de quase três séculos na legislação obreira (SEVERO, 2016, p. 149). A 
rotatividade de mão de obra tornar-se-á regra, e não mais situação excepcional: essa é uma das marcas mais profundas e também evidentes dos processos de terceirização.

\section{SOBRE O CONCEITO BÁSICO DE TERCEIRIZAÇÃO: ANÁLISE DO CASO BRASILEIRO}

Terceirização é nomenclatura conferida por inserir, na dinâmica da relação trabalhista, um terceiro; se o direito do trabalho fundou suas raízes na dogmática contratual bilateral individualizada quanto aos sujeitos, centrando-se nas figuras do empregado e do empregador, a pós-Modernidade trouxe a figura do trabalho flexível, cujas diretrizes são ditadas pela legislação de cada país.

Na esteira da flexibilidade em comento, determinado empregador poderá oferecer mão de obra a uma empresa, geralmente por meio de contratos civis (prestação de serviços, empreitada, etc.); os empregados da contratada trabalharão em prol da contratante, podendo tal fato dar-se até mesmo no ambiente do trabalho desta tomadora de serviços, e não da real empregadora. É possível também que uma empresa firme, com a administração pública, contratos de serviço ou de concessão por meio do qual ponha, a serviço do poder público, a mão de obra de seus empregados.

Nota-se, portanto, que há terceirização quando o empregado de determinada empresa não lhe presta serviços diretamente, mas o faz quanto à pessoa jurídica de direito privado ou público com a qual sua empregadora mantém algum tipo de contrato no qual seja estipulado o fornecimento de mão de obra à tomadora de serviços.

A questão de haver um terceiro, alheio às partes do contrato individual de trabalho (firmado entre o subordinado e seu empregador), sempre foi considerada uma espécie de intermediação de mão de obra, bastante comum no meio rural. Não há como negar que a terceirização se trata, salvo melhor juízo, de verdadeira intermediação de mão de obra, embora assim não seja definida por seu marco jurisprudencial mais relevante em sua trajetória no direito do trabalho brasileiro - a Súmula 331 do Tribunal Superior do Trabalho, que por muitos anos balizou o fenômeno.

A fragmentação do processo produtivo, bem como do capital que o sustenta, ultrapassa os limites da norma jurídica: diversos setores empresariais avançam, em passos largos, para delegar a terceiros a responsabilidade das diversas parcelas do processo produtivo. O resultado dessa fórmula é conhecido: ausência de fixação dos terceirizados em seus postos de trabalho, rebaixamento salarial, fragmentação e enfraquecimento de sindicatos e suas atividades, condições degradantes de trabalho, para além do aumento expressivo do número de acidentes do trabalho ocorridos com terceirizados (COUTINHO, 2015, p. 217-221). 
Como adiante se verá, em alguns países é permitida a terceirização indistintamente realizada, sendo prescindível a análise de sua vinculação à atividade nuclear ou àquelas periféricas desenvolvidas pela empresa. No Brasil ainda são adotados os critérios de "atividade-meio" e “atividade-fim” para se verificar a licitude ou não da relação trilateral descrita.

Ademais, é extremamente pertinente atentar para os motivos, em primeiro momento, da adoção dessa forma de contração pelas empresas nacionais na década de 1990, quando indiscriminadamente foram alegadas recessão, crises econômica e política, ou crise na empresa, tudo com o escopo de demonstrar ser indispensável a flexibilização produtiva. Na década posterior, em 2003, a totalidade das empresas elencava como necessidade para ampliação dos processos terceirizantes a competitividade internacional, a redução de custos e a mudança tecnológica, assim justificando a adoção dos contratos de trabalho flexíveis (DRUCK; FRANCO, 2012, p. 101-103).

Percebe-se assim que, mesmo havendo mudanças significativas na conjuntura macroeconômica e política entre as duas décadas em questão, o empresariado encontra novas razões para manter a exploração do trabalhador, retirando-lhe agora, além da mais-valia, também a dignidade, já que a terceirização desumaniza o ser humano mais do que qualquer outra forma de trabalho, tendo como base a "exploração flexível”.

Maurício Godinho Delgado (2016, p. 491) cita o Decreto-Lei 200/67 e a Lei 5.645/70 como os primeiros documentos normativos que permitiram a contratação de pessoal por meio de pessoa interposta (ou terceirização). De fato, os aludidos documentos normativos preveem que a administração pública deveria ser “descentralizada” e desincumbir-se de tarefas que não pertenciam ao escopo central do Estado. A questão era pontual, estratégica e até um tanto simples: poderia o ente público, por exemplo, contratar empresa especializada para realizar estudos sobre os municípios do País com maior porcentagem de analfabetos e, em seguida, exigir relatório sobre quais ações deveriam ser tomadas. A ideia inicial de terceirizar atividades prendia-se ao caráter especial de determinado trabalho, sendo inviável a contratação de pessoal na área, via concurso público, para realizar tais mapeamentos, por exemplo, a cada quinquênio.

A legislação de 1970 foi um tanto além: relacionou serviços de limpeza, conservação, transporte e assemelhados como objetos cuja preferência deveria recair sobre a contratação do Estado com entes privados que lhe prestassem serviços. Tais atividades, que são consideradas de apoio e meramente instrumentais quanto aos serviços prestados pela Administração, passariam a ser objeto de contratação por meio dos contratos do ente com empresas privadas. Não houve grande avanço legislativo no que respeita à terceirização no serviço privado: a Lei 6.019/74 é que trouxe, como novidade, esta relação trilateral de emprego, e a Lei 7.102/83 previu a possibilidade de contratação 
de vigilantes por meio de empresa interposta.

O mercado privado, porém, passou a desenfreadamente contratar serviços terceirizados de empresas prestadoras de serviço, não obstante as lacunas existentes no ordenamento jurídico brasileiro. O Tribunal Superior do Trabalho (TST), a mais alta corte da justiça trabalhista do Brasil, foi quem acabou por estabelecer regras para a terceirização, as quais passaram a ser observadas como limitação ao direito de contratar empresas prestadoras de serviço: assim surgiu a Súmula 331 deste tribunal, que estabeleceu critérios para a relação trilateral de emprego.

Em 1994, a Lei 8.949/94 flexibilizou ainda mais as relações de emprego: estabeleceu, no artigo 442 da CLT, a redação de um parágrafo único, segundo o qual "qualquer que seja o ramo de atividade da sociedade cooperativa, não existe vínculo empregatício entre ela e seus associados, nem entre estes e os tomadores de serviços daquela” (BRASIL, 2016a, p. 98). O fomento à terceirização tornou-se ainda mais explícito: um cooperado ligado a determinada cooperativa de prestação de serviços poderia executar serviços para empresa terceira, sem qualquer existência de vínculo empregatício nessas relações.

Em que pesem as legislações citadas, a regência sobre licitude ou ilicitude acerca do processo de terceirização no Brasil resta, até o momento, delimitado pelas teses centrais contidas na Súmula 331 do TST: permissão para que serviços sejam terceirizados nas chamadas “atividades-meio” da empresa e proibição de que estes se reportem à “atividade-fim”. O primeiro e grande problema que pode ser encontrado é a lacuna, seja dogmática ou jurisprudencial, acerca do obscuro conceito desses dois fatores que, por meros detalhes, podem ser facilmente confundidos pelo intérprete. E é nesse tipo de detalhe que provavelmente vive o diabo².

Podem ser definidas como atividade-meio as atividades secundárias existentes na empresa, que servem apenas como suporte para que esta possa realizar concretamente sua atividade-fim, ou seja, “aquela cujo objetivo a registra na classificação socioeconômica” (BARROS, 2016, p. 300). Toda empresa tem um objetivo central a cumprir, que consiste em sua própria essência, na razão de o empreendimento existir no mercado. Essa é a sua tarefa cimeira, ou seja, a atividade-fim (compreendido “fim” como “finalidade”). Atividade-meio opõe-se a tal conceito: são as parcelas periféricas da produção empresarial, que existem apenas como apoio ou suporte necessários à realização da finalidade a qual a empresa se propôs a fazer. Tal prática permitiria à empresa, em tese, dedicar-se de maneira mais detida ao seu objetivo primeiro, no afã de oferecer produtos e serviços de

\footnotetext{
${ }^{2}$ Descrito no cristianismo pelo evangelista João, em sua primeira carta, como "aquele que peca desde o princípio" (BÍBLIA, 2016, p. 2.045) e segue errante pela eternidade.
} 
maior qualidade aos seus clientes.

Como, porém, diferenciar com precisão esses dois conceitos? Na concretude do cotidiano isto se mostra frequentemente difícil (ou mesmo impossível). Jorge Luiz Souto Maior (2008, p. 143144) oferece exemplos: serviços de limpeza são tidos invariavelmente como pertencentes ao núcleo de atividades-meio da empresa. Seria possível afirmá-lo caso se tratasse de um hospital? A limpeza, neste ambiente, teria importância secundária ou de mero suporte às atividades-fim? Parece que não. Até mesmo em processos industriais não muito complexos essa tarefa se mostra difícil: o autor cita o exemplo de uma empresa que produz refrigerante. Como se pode determinar o início e o término da atividade-fim: quando se produz o líquido, ou quando este é engarrafado? Ao se colocar a tampa na garrafa de refrigerante, enfim, estar-se-ia a falar de atividade-meio? Não se vende refrigerantes em garrafas sem tampa. Toda essa imprecisão traz imensa insegurança jurídica aos trabalhadores e, como se verá, também às empresas.

Pela fórmula da terceirização,

[...] insere-se, no interior da relação efetiva entre trabalhador e seu tomador de serviços, uma empresa intermediária, chamada prestadora de serviços, que passa a responder pelo vínculo empregatício com o obreiro. Ao invés, portanto, da clássica sistemática pela qual o tomador de serviços habituais se enquadra como empregador da pessoa física que lhe presta serviços, separam-se, artificialmente, as relações, por meio da inserção, nessa seara, da empresa prestadora de serviços, que passa a deter o vínculo empregatício com o obreiro (DELGADO, 2015, p. 44-45).

A organização do labor funciona sobre um tripé: redução de cargos e salários na empresa, gestão flexível da força de trabalho (produzir o máximo no menor tempo possível, adaptando-se a produção às novas tecnologias e de acordo com a demanda existente no mercado) e, por fim, terceirização do maior número possível de atividades da empresa.

A fórmula sobredita, contudo, não visa propiciar melhores produtos aos consumidores, e sim produzir quantitativamente mais produtos e serviços investindo-se menos dinheiro para a oferta destes. Um dos vetores possíveis para alcançar esse desiderato é a terceirização. Não se trata de uma exigência da moderna sociedade do trabalho, e sim da fragmentação dos interesses e da força do proletariado.

A terceirização torna-se vantajosa para o capital porque rompe com a relação entre trabalhador e beneficiário final do serviço prestado, de maneira a impedir a integração do obreiro ao ambiente do trabalho e ao empreendimento nele realizado. Até mesmo pelo requisito da ausência de subordinação e pessoalidade diretas, o trabalhador torna-se (ou deve se tornar) “invisível” aos olhos dos demais. Não participará, por exemplo, da participação de lucros e resultados da empresa - lucros e resultados que tal obreiro empenhou-se em conquistar. 
As relações empregatícias dependem dos contratos firmados entre capitais (ou empresas), que facilmente podem romper-se; dessa forma, a rotatividade de mão de obra, sua flexibilidade para o trabalho em empresas as mais diversas impedem a aderência e a continuidade da relação havida para com o tomador de serviços. A ausência de pessoalidade, que também é exigência da Súmula 331 do TST, acaba por engendrar tal situação.

No mais, a empresa tomadora de serviços não investirá em saúde e segurança do trabalho, uma vez que tal obrigação é da empresa prestadora, ainda que o trabalho seja exercido no ambiente da primeira.

Ademais, a ação sindical resta prejudicada, já que no mesmo ambiente de trabalho há empregados pertencentes a um empregador, e terceirizados os mais diversos, que possuem categorias profissionais e seguem diplomas coletivos também diversos. A heterogeneidade aí presente não permite forjar qualquer identidade de classe, o que fragmenta interesses coletivos e praticamente impossibilita ações sindicais como, por exemplo, a greve. Talvez em função de questões desse jaez é que terceirizados percebam salários muito inferiores aos empregados da empresa contratante de serviços (DELGADO; AMORIM, 2014, p. 45-46).

Tais fatores negativos da terceirização são apenas exemplificativos. Tomando por base as escorreitas considerações de Rodrigo de Lacerda Carelli (2003, p. 191-223), há um sem-número de situações que podem afetar a dignidade do trabalhador mediante a terceirização, como a segregação presente no ambiente do trabalho, para além da social, que prolifera e distribui pobreza.

Retira-se do trabalhador a sua cidadania por afastá-lo da possibilidade de consumo devido a baixos salários, ínfimas chances de ascensão em suas carreiras, para além da discriminação entre os pares.

Não bastasse isso, conforme analisa Márcio Túlio Viana (2015, p. 50-53), também a terceirização submete pequenas empresas aos grandes conglomerados de capitais, já que o microempreendedorismo pode não cumprir a legislação trabalhista sem que isso cause espécie; pode, igualmente, sonegar direitos aos trabalhadores e não investir em prevenção de acidentes do trabalho, uma vez que a imagem da pequena empresa não restará tisnada na mesma proporção que poderia manchar a reputação de uma grande empresa, caso esta fosse autora de tantos aviltamentos à classe trabalhadora. 


\section{A TERCEIRIZAÇÃO COMO FATOR “INEVITÁVEL”: ANÁLISE DE EXPERIÊNCIAS JURÍDICAS ESTRANGEIRAS}

A inserção da terceirização na organização das relações de trabalho ganhou ênfase devido à velocidade em que se expandiu em escala global, na área privada e pública, como forma de diminuir custos ao contratante, em prejuízo do trabalho formulado em sua clássica moldura unilateral. Implicou consequências políticas importantes, como a quebra dos laços de solidariedade entre os trabalhadores e a fragilidade de suas representações e práticas sindicais.

Os diplomas normativos, assim como todo o ordenamento, devem ser seguidos pela sociedade em razão da força coativa existente por detrás de seus enunciados. A rigor, o ordenamento não possui, em princípio, relação alguma com a economia: por vezes ambos podem demonstrar interesses antagônicos. Por seu turno, quando economia e direito encontram-se em íntima relação, a norma se aproxima da vigência empírica, ou seja, “um complexo de motivos efetivos que determinam as ações humanas reais” (WEBER, 2014, p. 210). Apreender um conceito econômico e para este criar regramento jurídico nem sempre é tarefa fácil, dada a dinamicidade do capital e a lentidão que rege o processo de formulação de leis pelo parlamento. Em regra, são as situações fáticas (inclusive econômicas) que acabam por ditar o direito, e não o oposto.

\subsection{RELATOS ACERCA DA TERCEIRIZAÇÃO EM PAÍSES EUROPEUS: UMA ANÁLISE ESPECIAL DA LEGISLAÇÃO ITALIANA}

A terceirização surgiu nos meandros da lacuna do direito, tal como ocorreu em outros países. Em Portugal a própria legislação trabalhista passou a prever certa "flexibilidade funcional” quanto ao contrato individual de emprego, com amplitude do exercício do poder diretivo do empregador: poderá este, de forma unilateral, modificar provisoriamente o objeto da prestação subordinada de serviços, podendo até mesmo haver relativo "rebaixamento" da posição do trabalhador na empresa (FERNANDES, 2014, p. 196-204). Ademais, a subcontratação é regida como simples contrato individual de trabalho, podendo implicar consequências jurídicas para a tomadora de serviços quando há “união de contratos”, ou seja, a análise completa da relação trilateral estabelecida (MARTINEZ, 2015, p. 662-664).

Consoante observações da tratadista portuguesa Maria do Rosário Palma Ramalho (2012, p. 273-281), a relação trilateral de trabalho nas terras de além-mar dá-se, basicamente, pela adoção de contratos de trabalho temporário, que acabaram por ser acolhidos na redação do Código do Trabalho de 2009. Há, pois, três figuras: o trabalhador temporário, que firma contrato (a termo ou por prazo 
indeterminado) com uma empresa de trabalho temporário. Esta sempre figurará como a empresa contratada, cedente da mão de obra à chamada entidade utilizadora, que é a empresa tomadora de serviços.

Esse modelo teve origem nos países de tradição jurídica anglo-saxônicas, em que soluções mais flexíveis são adotadas pelos entes contratantes, mas não difere dos modelos adotados na França ou Alemanha. O sistema de terceirização é generalizado, podendo ser adotado em quaisquer das atividades da empresa, seja a principal ou as periféricas. O direito do trabalho lusitano, porém, toma o trabalho prestado de forma trilateral como exceção, restringindo-o a apenas algumas atividades taxativamente previstas em lei (muito especialmente no Decreto 260/2009, que busca harmonizar o processo de terceirização à Convenção 181 da Organização Internacional do Trabalho, ainda não ratificada pelo Brasil).

A existência de uma empresa de trabalho temporário exige autorização administrativa prévia, devendo prever de maneira muito clara qual o seu objeto. Ademais, precisa constituir uma caução, periodicamente atualizada, para que possa continuar a atuar no mercado. Junto com a entidade utilizadora (empresa tomadora de serviços), as empresas de trabalho temporário respondem solidariamente por eventual inadimplemento de obrigações trabalhistas.

Um dado que parece permear todo o sistema europeu é, todavia, bastante interessante: o direito à isonomia salarial entre trabalhadores temporários (terceirizados) e os empregados que executam, na empresa utilizadora de serviços, funções similares. Vale dizer: a terceirização tem limitação temporal, objeto de prestação de serviço previamente definida e, pelas regras gerais de direito do trabalho, a fórmula de "igual remuneração para igual trabalho" aparenta ter eficácia, e não mera vigência (RAMALHO, 2012, p. 281).

Ainda assim, contudo, o modelo é considerado prejudicial ao trabalhador e, por isso mesmo, bastante criticado entre os juristas de além-mar: enfraquece-se a atuação sindical, não se permite ao trabalhador terceirizado a oportunidade de ascensão funcional dentro da empresa e impede a criação de novos postos de trabalho, os quais deveriam ser preenchidos por trabalhadores cuja contratação se daria por tempo indeterminado.

Também na Espanha, tal como no Brasil, a contratação de pessoas por empresa interposta é, em princípio, ilícita. A terceirização (ou subcontratação) é permitida como exceção, devendo ser temporária. As empresas envolvidas em tais processos são solidariamente responsáveis pelos pagamentos das verbas trabalhistas, dando-se destaque especial ao salário. Tal fator possui relevância porque é permitido ao trabalhador terceirizado queixar-se diretamente ao representante de empregados da empresa tomadora de serviços, ou seja, da contratante. 
Da mesma maneira, tais empresas são solidariamente responsáveis por informar aos trabalhadores os riscos profissionais existentes, investir na segurança do trabalho, bem como prevenir e proteger os trabalhadores em caso de infortúnios profissionais. No mais, é obrigatório à empresa tomadora de serviços estipular previamente o prazo para duração do contrato, bem como objeto e local da prestação de serviços, descrevendo quais são os riscos profissionais existentes na empresa e como se dará a prevenção contra estes (ALONSO OLEA, 2009, p. 175-178).

A legislação espanhola segue aproximadamente as mesmas diretrizes da experiência jurídica de Portugal, com algumas particularidades a serem sublinhadas: com a reforma de flexibilização do mercado de trabalho em 2006, o Reino da Espanha passou a ter a legislação trabalhista mais parecida com a brasileira. O sistema de equiparação salarial entre empregados da tomadora e da prestadora não se encontra presente no estatuto dos trabalhadores, e sim na jurisprudência do país. O motivo é simples: inequivocamente, trabalhadores terceirizados apresentam índices de acidente de trabalho bastante superiores aos dos empregados da tomadora de serviços. Logo, a equiparação de direitos mínimos, incluindo igualdade de remuneração e responsabilidade solidária das empresas, tornou-se regra (ALBUQUERQUE, 2014, p. 495-496).

De todo modo, há previsões importantes: empresas sem objeto social bem definido - ou, em outras palavras, pessoa física ou jurídica que somente existe como empresa prestadora de serviços são ilegais. Não se admite a existência de empresa meramente “prestadora de mão de obra”, formando-se o vínculo empregatício diretamente com a tomadora. Para além de tais previsões, a terceirização na construção civil é admitida, mas regida por lei especial (Lei 32, de 18 de outubro de 2006): limita-se a terceirização por tempo indeterminado e as empresas são rigorosamente fiscalizadas quanto à segurança no trabalho existente na construção civil.

Mesmo passados mais de dez anos após a flexibilização das leis trabalhistas, o desemprego na Espanha não diminuiu e, além disso, a média salarial do trabalhador foi rebaixada. Uma crítica comumente encontrada nos sistemas europeus quanto à terceirização, aliás, é o frágil vínculo entre trabalhadores e sindicatos, uma vez que subcontratação importa em rotatividade de mão de obra. Desta forma, conquistas sindicais a empregados de determinadas empresas de uma categoria profissional específica acabam por não melhorar expectativas salariais dos trabalhadores terceirizados, cuja representatividade é, em termos coletivos, praticamente nula (ALBUQUERQUE, 2014, p. 488).

Essa tendência de legislar a granel em tempos de crise também é verificada na França. Conforme Thomas Piketty (2017, p. 177-181), a política de produção do direito francês tem dado ênfase aos processos de terceirização por meio do uso crescente do trabalho temporário, e esta ânsia 
por “competitividade” certamente não surgiu pela criação de normas trabalhistas subitamente rígidas. O modelo que se tenta implementar diz respeito à valorização excessiva dos diplomas coletivos e dos acordos de empresa, exatamente num momento em que sindicatos se tornam cada vez com menor poder de negociação. Esse tipo de política trabalhista, que transforma a legislação do trabalho numa espécie de “salada” (palavras de Piketty), assemelha-se à promulgada Lei 13.429, de 31 de março de 2017, que trouxe normatividade à terceirização sem sequer aguardar pelos debates que estão a ser elaborados no Legislativo brasileiro.

De qualquer forma, pode-se considerar o direito italiano como referencial para se tratar do tema da terceirização, uma vez que a península Apenina foi a primeira a regulamentá-la de forma detalhada; assim o Brasil busca fazê-lo por meio do Projeto de Lei da Câmara (PLC) 30/2015, em análise no Senado Federal (BRASIL, 2015), ainda que com a sanção presidencial da Lei 13.429/2017.

A Lei Biagi (Lei 30, de 14 de fevereiro de 2003) foi uma proposta de possível modernização e flexibilidade dos contratos de trabalho bastante discutida no parlamento italiano durante o governo do primeiro-ministro Sílvio Berlusconi. Trouxe conceitos novos que, em tese, buscavam regulamentar o que a economia, na prática, já vinha fazendo à margem da lei: intermediação de mão de obra, antes absolutamente proibida, sob qualquer epíteto. A Lei foi mais esmiuçadamente tratada pelo Decreto Legislativo 276/2003 (GHERA, 2012, p. 368).

Cumpre sublinhar seus principais aspectos. Inicialmente, prevê-se a figura do appalto di servizi, tipologia inexistente no Brasil. É semelhante, grosso modo, ao contrato de prestação de serviços: trata-se de uma figura intermediária entre o trabalhador autônomo e o subordinado, ao qual se costuma denominar parassubordinado (FURQUIM, 2015, p. 40).

Trata-se, pois, de um contrato por meio do qual uma parte (trabalhador autônomo) se obriga a prestar um serviço ou produzir algo, com absoluta autonomia, mas com obrigação de resultado quanto à empresa contratante. Esta, no entanto, é quem deve propiciar ao trabalhador os meios necessários para a realização do serviço contratado, assumindo, para si, o risco do empreendimento. No caso de subcontratação de pessoas por parte do profissional que exerce tal serviço, este e a empresa beneficiária dos serviços prestados ficam solidariamente responsáveis pelo pagamento das verbas remuneratórias dos subcontratados, havendo o prazo de um ano para reclamação dessas verbas. Ultrapassada essa limitação temporal, a contratante e o profissional autônomo permanecem solidariamente responsáveis, pelo menos, quanto ao adimplemento das obrigações previdenciárias dos trabalhadores subcontratados (FAILLA; ROTONDI, 2012, p. 183-187).

Outra figura a ser examinada é o contrato de lavoro a progetto. Nesse caso a parassubordinação aparece ainda mais claramente: trata-se de contrato por meio do qual não existe 
relação de subordinação, e sim de coordenação entre o trabalhador e a empresa contratante. O profissional deverá desenvolver um projeto em favor da contratante, com jornada de trabalho estipulada, em prazo determinado ou determinável até a conclusão do serviço contratado.

Há necessidade de se especificar concretamente, no instrumento negocial (contrato de lavoro a progetto), qual é o projeto desenvolvido, e não meramente o objeto do contrato descrito de forma ampla e genérica, pois aí haverá reconhecimento da existência de subordinação, e não de coordenação de forças produtivas.

A legislação prevê que o trabalho por projeto não terá duração inferior a 30 dias por ano com a mesma empresa contratante, pois isto se trataria de mero trabalho eventual, exceto no caso em que se perceba renda superior a cinco mil euros. Havendo tal pagamento, presume-se que o contrato por projeto, ainda que com duração inferior a trinta dias, não seja meramente eventual.

Tal figura prevê alguns direitos trabalhistas ao prestador de serviços, o qual não age de forma plenamente autônoma, mas não chega a subordinar-se à empresa tomadora de serviço: o contrato de trabalho não é extinto, e sim suspenso nos casos de gravidez ou doença e acidente do trabalho. O profissional deverá perceber retribuição similar àquela que, em média, o mercado costuma oferecer aos trabalhadores autônomos que exercem atividades similares às desenvolvidas nesta relação que, frise-se, é de coordenação de interesses. Todas as normas de segurança e saúde do trabalho, incluindo repouso semanal remunerado, devem ser respeitadas pela tomadora de serviços. Por fim, caberá pagamento de aviso prévio no caso de rompimento antecipado do contrato.

A grande dificuldade existente nessa forma de prestação de serviços é diferenciar até que ponto a coordenação não se confunde com subordinação, o que pode ser tarefa árdua no exame de casos concretos. Também o desenvolvimento de projetos vários, sempre relacionados à mesma empresa ou ao grupo econômico que participa, poderá indicar tentativa de fraude à legislação trabalhista italiana (SANTORO-PASSARELLI, 2015, p. 15-47).

A pessoalidade, de fato, é presente nesse contrato, mas se a prestação de "trabalho por projeto" dar-se de forma não eventual, a subordinação (que é sublimada, eis que surge, como figura contratual, a colaboração) poderá restar configurada. Também o mesmo poderá ocorrer em relação à administração pública, sem, contudo, configurar-se efetivamente em relação de emprego, ante as exigências da Constituição italiana para admissão em serviço público. As verbas trabalhistas decorrentes desse reconhecimento, contudo, serão devidas pelo ente público em caso de culpa ou dolo (FOCCILLO, 2013, p. 216-218).

Resta, por fim, a subadministração do trabalho (equiparável ao que se conhece, no Brasil, como terceirização em sentido estrito), que adota a conhecida fórmula da relação trilateral de 
emprego; não há qualquer previsão quanto a eventuais diferenciações entre atividade-meio e atividade-fim da empresa. No contrato firmado entre prestadora e tomadora de serviços, deve-se informar o número de trabalhadores terceirizados, o enquadramento profissional, local do trabalho, cuidados com segurança e saúde do trabalho, etc.

Há dois aspectos, porém, que despertam atenção: o primeiro deles é que a terceirização, em regra, se dá por prazo determinado. Nesse sentido, a Itália segue as mesmas diretrizes existentes em outros países europeus já citados neste tópico. Serviços terceirizados somente podem ser contratados por prazo indefinido caso estejam presentes em rol taxativo previsto na lei. No mais, o trabalhador terceirizado deverá ter tratamento salarial isonômico em relação aos empregados da contratante (DAL BON, 2015, p. 51). Ademais, os trabalhadores terceirizados sempre se vincularão aos sindicatos da categoria da tomadora de serviços, e a responsabilidade desta pelo pagamento das verbas trabalhistas é solidária (OCCHINO, 2014, p. 82-85).

Todo esse arcabouço legislativo italiano demonstrou-se ineficaz quanto à proposta de melhoria das condições de vida dos trabalhadores, pois a rotatividade de mão de obra acabou por enfraquecer sindicatos e a coesão dos trabalhadores para planos de ação conjunta. Ainda que se tenha garantido paridade salarial entre empregados da tomadora e terceirizados, verbas deixam de ser pagas pelo fato de o contrato dar-se, em regra, de forma temporária. A instabilidade salarial do trabalhador italiano acaba por restar evidente, uma vez que se sua empregadora firmar contrato com outra tomadora que pague, aos próprios subordinados, salários menores que o da antiga empresa tomadora, quem sentirá essa defasagem será o terceirizado. Por fim, seu caráter interino sempre acaba por retirar-lhe a condição de membro efetivo da empresa, dificultando a integração entre trabalhadores no mesmo ambiente do trabalho. As possibilidades de ascensão profissional e estabilização de relações contratuais, se não nulas, são mínimas. Após a reforma, o número de empregos ofertados pelo mercado manteve-se sem grandes alterações, mas o rendimento médio do trabalhador foi consideravelmente rebaixado (GRANDI, 2007, p. 1717).

\subsection{A TERCEIRIZAÇÃO DISCUTIDA NO PARLAMENTO BRASILEIRO}

Se a experiência jurídica italiana e também a europeia, de maneira geral, não recomendam a regulamentação da terceirização como conquista dos trabalhadores, certamente pior juízo se fará quanto ao PLC 30/2015 (BRASIL, 2015). Este não prevê, em hipótese alguma, paridade salarial entre terceirizados e trabalhadores da empresa tomadora/beneficiária dos serviços. Permite a prática da terceirização tendo o prazo indefinido como regra: temporária é apenas a passagem do trabalhador 
pelas empresas tomadoras, e não o contrato entre estas e as prestadoras; inexistem limitações temporais para a terceirização no projeto citado, assim como não há proibição de que determinadas atividades sejam terceirizadas, ao contrário de todo o arcabouço trazido pelas legislações europeias.

Além disso, os empregados terceirizados vincular-se-ão ao sindicato a que se encontram vinculados os subordinados da empresa tomadora de serviços se a prestadora pertencer à mesma categoria econômica, previsão que, na prática, contemplará poucos casos.

Não bastassem tais previsões, o artigo 14 do mencionado projeto causa acinte até mesmo à dogmática jurídica trabalhista: quando houver “contratação sucessiva” de trabalhadores terceirizados para que sua prestação de serviços se mantenha no tempo, com admissão de empregados da antiga contratada, “a nova contratada deve assegurar a manutenção do salário e dos demais direitos previstos no contrato anterior” (BRASIL, 2015).

Essa previsão remete à pessoalidade em face da figura do empregado terceirizado, que, na forma do PLC 30/2015, se contratado por outra empresa que venha a terceirizar serviços, deverá esta manter seu patamar salarial. Pergunta-se: por que razão, se tal empregado é desejado pela tomadora de serviços, não se torna seu próprio empregado? A dúvida é pertinente porque traz aparência de legalidade a uma situação que sempre foi ilegal na dogmática trabalhista brasileira e alienígena. Um trabalhador poderia prestar serviços à mesma tomadora pelo prazo de dez ou vinte anos, mas sua empregadora formal, neste ínterim, poderia ser uma, duas ou diversas empresas.

O artigo 14 do PLC 30/2015, em apreciação no Senado da República, permite que a empresa tomadora de serviços solicite, da nova contratada, o estabelecimento de relação de emprego com terceirizado da antiga prestadora de serviço, fato que caracteriza pessoalidade em relação à figura do trabalhador. Se o intento do projeto é conferir segurança jurídica ao processo de terceirização, este restará frustrado, ainda que numa rasa interpretação dos artigos $3^{\circ}$ e $9^{\circ}$ da Consolidação das Leis do Trabalho (CLT). O PLC 30/2015, nesse sentido, choca-se com determinação nele mesmo estabelecida: trata-se do artigo $5^{\circ}, \S 3^{\circ}$, que considera nulo de pleno direito o estabelecimento de cláusula que imponha, à contratada, proibição ou exigência de contratação de empregado da antiga prestadora.

Em setembro de 2016 foi apresentado o Projeto de Lei do Senado (PLS) 339/2016 (BRASIL, 2016b), com o declarado objetivo de substituir o PLC 30/2015. De fato, como exposto na justificativa do projeto, o novo texto é muito mais rigoroso quanto a certos aspectos. De acordo com seu artigo $6^{\circ}$, a empresa tomadora de serviços terá de comunicar ao sindicato da categoria profissional preponderante os motivos técnicos ou econômicos que justificam a terceirização, redução de custos ou metas pretendidas, entre outras exigências. 
No mais, conforme o artigo $8^{\circ}$ do substitutivo, serão exigidas da empresa prestadora de serviços um extenso rol de documentos, como certidão negativa de débitos, certificado de regularidade no recolhimento do Fundo de Garantia do Tempo de Serviço (FGTS), capital social integralizado apto a garantir a execução do serviço, com valor mínimo de $\mathrm{R} \$ 500.000,00$ (quinhentos mil reais), comprovante de entrega da Relação Anual de Informações Sociais (RAIS), certidão de ausência de infrações, expedida pelo Ministério do Trabalho, e de inexistência de execuções, declarada pela Justiça do Trabalho.

A maior alteração, contudo, é a vedação à contratação de empresa especializada para realizar atividades inerentes à tomadora de serviços, conceito este que é o de atividade-fim, previsto na Súmula 331 do Tribunal Superior do Trabalho. Ainda que com melhor redação - se comparado ao PLC 30/2015 -, o PLS 339/2016, do Senado Federal, não estabelece isonomia salarial entre empregados da tomadora e da prestadora de serviços, para além de pouco fortalecer a atuação sindical em defesa dos trabalhadores terceirizados.

O Executivo, porém, desejou imprimir à terceirização regulamentada o caráter de urgência, e assim o fez quanto ao Projeto de Lei 4.302/98, já em trâmite há quase vinte anos, o qual é anterior (e, em grande medida, muito mais permissivo) que os Projetos de Lei da Câmara e do Senado, já citados. O resultado viu-se em 31 de março de 2017; qual seja, a promulgação, nessa data, da Lei 13.429. Tal diploma normativo prevê a terceirização à larga, não estabelecendo limitações quanto às atividades da empresa passíveis de serem delegadas a terceiros; além disso, prevê responsabilidade subsidiária da empresa tomadora de serviços, dificultando, ao trabalhador, seu acesso mais ágil ao crédito trabalhista. Tais considerações nem mais existiam nos projetos de lei ora em discussão no Senado da República.

Não se pode ainda olvidar que a Lei 13.429/17 admite como lícito o fenômeno da “quarteirização”, ou seja, permite a subcontratação de trabalhadores pela empresa prestadora de serviços (artigo $4^{\circ}$-A, $\$ 1^{\circ}$, da citada lei). Em grande parte dos países europeus essa prática é proibida, à exceção da Espanha, que apenas proíbe expressamente a quarteirização no ramo da construção civil.

Não bastasse isto, a empresa tomadora poderá (e não deverá) estender aos terceirizados serviços médicos, ambulatorial e de refeição propiciados aos seus empregados. Aparentemente, tal norma torna ainda mais precária as relações de emprego regidas pelo modelo terceirizante, ainda que comparada com os projetos legislativos em discussão no Senado. Inexiste limitação temporal para a terceirização, ao contrário dos países europeus citados, em que a terceirização assume a fórmula da rotatividade como algo excepcional; no Brasil, o contrato trilateral ganha contornos de regra.

Não se verifica, nos países europeus, o óbice criado no direito brasileiro pela Súmula 331 do 
TST, qual seja, a separação entre terceirização nas atividades-meio da empresa (em princípio lícitas) e nas atividades-fim do empreendimento. De fato, parece não haver motivo plausível para tal discussão que, do início ao cabo, serve mais para confundir o Judiciário na aplicação do direito e não possui fundamento ontológico que possa ser considerado válido: por que atividades-meio são “inferiores” às atividades-fim? A marca da terceirização, se permitida, deverá ser a da excepcionalidade, restrita a necessidades pontuais da empresa como, por exemplo, é o caso do trabalho temporário.

Impende observar que os projetos de lei acerca do fenômeno da terceirização, inclusive este que se tornou lei, vêm sendo discutidos pelo parlamento em momento de crise financeira. O direito do trabalho e suas mínimas garantias pertencem ao núcleo das chamadas cláusulas pétreas da Constituição Federal. Conforme Gilmar Ferreira Mendes e Paulo Gustavo Gonet Branco (2015), tais direitos são insuscetíveis de modificação para pior ou de supressão, porque a dignidade da pessoa humana, fundamento da República, concebe o homem também em sua dignidade social.

Ao falar-se já nos fundamentos da República em valor social do trabalho, construção de uma sociedade justa e solidária, redução de desigualdades sociais, etc., fica claro que o constituinte desejou preservar tais direitos também como cláusulas pétreas (MENDES; BRANCO, 2015, p. 129).

Pode-se extrair do texto constitucional a defesa da isonomia salarial, com a proibição de discriminações injustas, para além do direito fundamental à sindicalização e ao fortalecimento desses entes associativos, o que parece tisnado pelos projetos em trâmite no parlamento brasileiro. Nesse sentido, há um tema que vem sendo bastante discutido nos tribunais europeus e também no Supremo Tribunal Federal, que expressamente admite sua existência: a cláusula de proibição do retrocesso social.

Firmou-se jurisprudência no sentido de que, quando o Estado já atingiu certo grau de direitos sociais exigíveis, não há possibilidade de extinguir direitos sociais ou limitá-los de forma tal que essa limitação atinja seu núcleo essencial. Geralmente essa jurisprudência se firma em oposição às chamadas "políticas de austeridade" dos governos, que buscam impor sacrifícios demasiados à população e suprimir direitos em prol de diminuir gastos sociais. Qualquer proposta legislativa que defenda a terceirização acaba por engendrar retrocessos sociais, em maior ou menor grau.

Como já asseverado, o Estado de bem-estar social é a tônica do mundo pós-Guerra. A Constituição Federal de 1988 possui este viés: promulgada um ano antes da queda do Muro de Berlim, confere ao Brasil feição social-democrata, que se situa como terceira via entre o capitalismo de Estado (ou “socialismo”), capitaneado pela União Soviética, e o capitalismo ultraliberal, cujos símbolos maiores eram os Estados Unidos da América e o governo de Ronald Reagan. 
Nesse diapasão, os tribunais constitucionais têm buscado preservar as conquistas sociais já existentes e, em tempos de crise, buscam ponderar a proibição do retrocesso social com a ideia de “limites do sacrifício”. Trata-se, nas palavras de Gilmar Mendes, de não pensar a proibição de retrocesso social em caráter absoluto; atendendo a princípios como o da proporcionalidade, não poderá haver retrocessos sociais, mas, diante de certas conjunturas econômicas, seria possível admitir-se certos sacrifícios, desde que não afetem o núcleo central dos direitos sociais. Trata-se, pois, da chamada "jurisprudência de crise”, adotada em momentos de recessão econômica (MENDES; BRANCO, 2015, p. 644-647).

Só se pode admitir jurisprudência de crise, ou criação de normas jurídicas para momentos de crise financeira, quando a verdadeira crise se encontra no Estado. O modelo intervencionista, como bem recorda Lênio Luiz Streck (2013, p. 83-95), não beneficiou apenas a classe trabalhadora; em verdade, alavancou todo o processo produtivo industrial, como ocorre com a construção de usinas hidrelétricas, estradas, políticas de financiamentos empresariais de pequena, média ou grande monta, etc.

Ao atingir-se determinado ponto na evolução histórica do Estado de bem-estar social, não poderá mais haver retornos. Parcela da elite, porém, deseja o Estado social para ela, e apresenta o receituário liberal ou de Estado-polícia às classes menos favorecidas. Há mais de sessenta anos Evaristo de Moraes Filho (1956, p. 238) previa esse receituário, quando afirmava que o direito do trabalho é, por excelência, um “direito de crise”: é o pacto mínimo de civilidade estabelecido pela crise existente na relação entre capital e trabalho.

Ainda com Lênio Streck (2013) e Evaristo de Moraes Filho (1956), pode-se afirmar que certas instituições não são necessariamente revogadas, mas esvaziadas em seu conteúdo. Após bem servir a interesses setoriais, busca-se o enfraquecimento do Estado. Os direitos do trabalhador - sejam eles remuneratórios, de aperfeiçoamento profissional, de proteção à sua saúde ou de fortalecimento de seus interesses coletivos, representados no ente sindical - podem restar intocados na Constituição, mas esvaziados em conteúdo.

A massa de trabalhadores terceirizados enquadra-se perfeitamente na definição acima lançada: o receituário observado na Europa, descrito no tópico anterior, demonstra a similaridade dos efeitos prejudiciais ao sindicalismo, à ascensão profissional e ao rendimento médio do trabalhador nos países em que a terceirização foi regulamentada, embora nenhum direito trabalhista tenha sido formalmente revogado.

O enfraquecimento ou perda de substância do Estado de bem-estar social não se dá mais por processos de ruptura, e sim nas discussões existentes nas casas legislativas solícitas à crise, ganhando 
guarida nos tribunais constitucionais por meio de "jurisprudência de crise”, ou seja, a ela submissa. Contra a crise, somente será possível um antídoto: o direito. Mais especificamente, o “direito de crise”, traço característico do direito do trabalho.

\section{CONSIDERAÇÕES FINAIS}

Ao menos em aparência, o surgimento da terceirização não é um fenômeno que, de per si, possa ser qualificado negativamente. Com frequência, empresas e administração pública necessitam de serviços técnicos altamente especializados para a prestação de trabalhos específicos como, por exemplo, conhecer as demandas de determinada região ou pesquisar a viabilidade comercial de algum segmento em dado espaço regional. Para isso, todavia, o Código Civil já tem, de há muito, normativa específica: contrato de prestação de serviços, que é a peça jurídica inicial a propulsionar o fenômeno analisado. Todo problema reside, pois, em sua generalização como fórmula para diminuir custos empresariais.

Mais que em outros quadrantes do globo a terceirização, no Brasil, é encarada como fórmula para precarização de empregos e aumento desenfreado dos lucros do capital, a expensas da dignidade do labor humano. Não se trata de frase meramente retórica: princípios basilares do direito do trabalho, de densa normatividade jurídica, são postos em xeque. A fórmula terceirizante diminui a média dos salários oferecidos no mercado, enfraquece a ação sindical, impede a integração dos trabalhadores na empresa e torna o trabalho sempre intermitente, transitando entre ambientes diversos.

A experiência jurídica acima narrada não advém apenas do Brasil, mas de todos os países que permitiram e regulamentaram o fenômeno da terceirização. Prevista na Súmula 331 do Tribunal Superior do Trabalho e agora em projetos de lei discutidos no parlamento brasileiro, nem sequer há norma que garanta, ainda que de forma complessiva, isonomia remuneratória entre empregados da empresa prestadora e tomadora de serviços (à exceção do previsto no trabalho temporário). No Brasil, ao contrário de todos os países aqui estudados, centra-se na definição de conceitos altamente imprecisos, propositalmente utilizados para a prática em comento. Demonstrou-se, na prática, a dificuldade em se diferenciar “atividade-fim” (ou “inerente”) e “atividade-meio” (ou “não-inerente”) de determinada empresa, para fins de proibir a terceirização quanto à primeira, permitindo-a à larga no segundo caso. Não existe sequer um rol exemplificativo - e menos ainda taxativo, como ocorre na Itália - em relação às atividades que poderão ou não ser terceirizadas.

Outra questão em que o Brasil parece não tomar como escorreita as lições trazidas pela experiência jurídica estrangeira é tratar a terceirização como regra, e não como caso excepcional. 
Países europeus admitem terceirização apenas temporariamente e, caso se ultrapasse o limite previsto, a relação jurídico-laboral forma-se diretamente com a tomadora de serviços, rumo ao que os portugueses denominam como estabilização do contrato. No Brasil - e o parlamento reforça esta tendência nos projetos de lei discutidos - um trabalhador pode, por longo período de tempo, prestar serviços periféricos a determinada empresa por meio de contrato de prestação de serviços firmado entre ela e a empresa prestadora, que é sua empregadora formal. O desnível salarial e a segmentação, dentro do mesmo ambiente do trabalho, de trabalhadores terceirizados e aqueles da própria empresa tomadora, parece criar castas diferentes num mesmo local, impedindo a integração dos terceirizados com seus pares.

Terceirização não significa, necessariamente, modernização das relações de trabalho, e nem mesmo a flexibilidade consegue ser sua característica: trata-se da lógica pura e simples de diminuir salários e custos, permitindo às empresas que, por meio de agente interposto, possam contratar trabalhadores por salários menores que o de seus empregados, reduzindo ao máximo cargos e funções os quais geralmente representam, nas empresas, os postos de trabalho que oferecem melhores condições de ascensão profissional ao trabalhador. Os projetos de lei, na melhor das hipóteses, buscam legalizar e exigir uma série de garantias para pagamento de verbas trabalhistas e previdenciárias da figura do agente interposto, que sempre foi banida até mesmo pela dogmática jurídica desse ramo especializado do direito.

Em momentos de crise do capital financeiro, já ensina a experiência, não se deve legislar. Não se pode conceber um direito “de crise”, legitimado posteriormente por “jurisprudência de crise”, que permita a institucionalização de situações excepcionais. O Brasil já enfrentou crises econômicas antes e depois de o fenômeno da terceirização tornar-se prática corriqueira, na década de 1990. Nunca houve aumento de empregos com economia em recessão, ao passo que sempre houve mais postos de trabalho à medida que o setor produtivo por eles demandava. A legislação trabalhista não foi e jamais será o incentivo ou o empecilho para criação de empregos: isto dependerá sempre das políticas que determinam o Estado de bem-estar social, o qual intervém em políticas econômicas, industriais e de seguridade aos desempregados.

O Estado de bem-estar social torna-se, gradativa e pontualmente, enfraquecido por medidas legislativas que acabam por negar - no plano fático, e não formal - direitos elementares da classe trabalhadora, como isonomia salarial, possibilidade de ascensão profissional, fortalecimento de sindicatos e não discriminações entre trabalhadores num mesmo ambiente do trabalho. Os projetos de lei analisados, em que pese o fato de trazerem alguns méritos já citados, acabam por tentar oferecer resposta inadequada ao desemprego provocado pela crise financeira: é justamente nesses momentos 
que cumpre ao direito brasileiro e aos seus intérpretes, fiéis à sua concepção garantista, não aceitar retrocessos sociais. As crises do capitalismo são passageiras; a lei, uma vez aprovada, é perene. Deve essa reflexão servir não apenas aos juristas, mas também à sociedade e a quem a representa, qual seja, o parlamento brasileiro.

\section{REFERÊNCIAS}

ALBUQUERQUE, Bruna Maria Jacques Freire de. Subcontratación y precarización del trabajo: un estudio comparativo de la norma laboral brasileña y española. Salamanca: Universidad de Salamanca, 2014.

ALONSO OLEA, Manuel. Derecho del Trabajo. 27. ed. Madrid: Civitas, 2009.

ANTUNES, Ricardo. Adeus ao trabalho? Ensaio sobre as metamorfoses e a centralidade no mundo do trabalho. 15. ed. São Paulo: Cortez, 2011.

BARROS, Alice Monteiro de. Curso de Direito do Trabalho. 10. ed. São Paulo: LTr, 2016.

BÍBLIA Sagrada. 7. ed. São Paulo: Ave Maria, 2016.

BRASIL. CLT Acadêmica e Constituição Federal. 13. ed. São Paulo: Saraiva, 2016a.

BRASIL. Lei 13.429, 31 de março de 2017. Altera dispositivos da Lei no 6.019, de 3 de janeiro de 1974, que dispõe sobre o trabalho temporário nas empresas urbanas e dá outras providências; e dispõe sobre as relações de trabalho na empresa de prestação de serviços a terceiros. Diário Oficial da União, Brasília, DF, 31 mar. 2017. Disponível em: <https://goo.gl/AYnrcv>. Acesso em: 1 dez. 2016.

BRASIL. Projeto de Lei da Câmara no 30, de 2015. Dispõe sobre os contratos de terceirização e as relações de trabalho deles decorrentes. Texto oficial remetido ao Senado Federal em 28/04/2015. Disponível em: <https://goo.gl/eCqzpK>. Acesso em: 23 set. 2016.

BRASIL. Projeto de Lei do Senado n 339, de 2016. Dispõe sobre os contratos de terceirização por pessoas de natureza jurídica de direito privado e as relações de trabalho deles decorrentes. Texto oficial: 12/09/2016b. Disponível em: <https://goo.gl/fQ7pKg>. Acesso em: 1 dez. 2016.

CARELLI, Rodrigo de Lacerda. Terceirização e intermediação de mão-de-obra: ruptura do sistema trabalhista, precarização do trabalho e exclusão social. Rio de Janeiro: Renovar, 2003.

CASTEL, Robert. As metamorfoses da questão social: uma crônica do salário. Tradução Iraci D. Poleti. 6. ed. Petrópolis: Vozes, 1998.

COUTINHO, Grijalbo Fernandes. Terceirização: máquina de moer gente trabalhadora. São Paulo: LTr, 2015.

DAL BON, Emiliana M. La somministrazione di lavoro. Milano: Giuffrè, 2015. 
DELGADO, Gabriela Neves; AMORIM, Hélder Santos. Os limites constitucionais da terceirização. São Paulo: LTr, 2014.

DELGADO, Maurício Godinho. Capitalismo, trabalho e emprego: entre o paradigma da destruição e os caminhos da reconstrução. 2. ed. São Paulo: LTr, 2015.

DELGADO, Maurício Godinho. Curso de Direito do Trabalho. 15. ed. São Paulo: LTr, 2016.

DRUCK, Graça; FRANCO, Tânia. A perda da razão social do trabalho: terceirização e precarização. São Paulo: Boitempo, 2012.

DUMÉNIL, Gérard; LÉVY, Dominique. La crisis del neoliberalismo. Tradução Elizabeth Scott Blacud. Madrid: Lengua de Trapo, 2014.

EWALD, François. L’Etat Providence. Paris: Bernard Grasset, 1986.

FAILLA, Luca; ROTONDI, Francesco. La somministrazione di lavoro: differenze con il contratto a termine e l'appalto di servizi. Milano: Giuffrè, 2012.

FERNANDES, António Monteiro. Direito do Trabalho. 17. ed. Coimbra: Almedina, 2014.

FERNANDES, Florestan. A revolução burguesa no Brasil: ensaio de interpretação sociológica. 5. ed. São Paulo: Globo, 2005.

FOCCILLO, Antonio. Il rapporto di lavoro del pubblico impiego: evoluzione e commento. Roma: Aracne, 2013.

FURQUIM, Maria Célia de Araújo. Nem empregado, nem autônomo: parassubordinado. São Paulo: LTr, 2015.

GHERA, Edoardo. Diritto del Lavoro. 17. ed. Bari: Cacucci, 2012.

GRANDI, Gaetano Zilio. Dieci anni di flessibilità e dieci punti di riflessione. Lavoro e Previdenza Oggi, Milano, v. 34, n. 12, p. 1.714-1.717, dic. 2007.

LUKÁCS, Georg. História e consciência de classe: estudos sobre a dialética marxista. Tradução Rodnei Nascimento. 2. ed. São Paulo: Martins Fontes, 2012.

MARTINEZ, Pedro Romano. Direito do Trabalho. 7. ed. Coimbra: Almedina, 2015.

MENDES, Gilmar Ferreira; BRANCO, Paulo Gustavo Gonet. Curso de Direito Constitucional. 10. ed. São Paulo: Saraiva, 2015.

MORAES FILHO, Evaristo de. Introdução ao Direito do Trabalho. v. 1. Rio de Janeiro: Forense, 1956.

OCCHINO, Antonella. L'interposizione nei rapporti di lavoro: somministrazione di lavoro e distaccodi lavoratori subordinati. Roma: Giuridica, 2014.

PIKETTY, Thomas. Às urnas, cidadãos! - Crônicas 2016-2018. Tradução André Telles. Rio de Janeiro: Intrínseca, 2017. 
PURCALLA BONILLA, Miguel Ángel. El trabajo globalizado: realidades y propuestas. Pamplona: Aranzadi, 2009.

RAMALHO, Maria do Rosário Palma. Tratado de Direito do Trabalho: situações laborais individuais. v. 2. 4. ed. Coimbra: Almedina, 2012.

SANTORO-PASSARELLI, Giuseppe. I rapporti di collaborazione coordinata e continuativa: uma fattispecie in via di trasformazione? Napoli: Jovene, 2015.

SATO, Leny; SCHMIDT, Maria Luísa Sandoval. Psicologia do Trabalho e Psicologia Clínica: um ensaio de articulação focalizando o desemprego. Estudos de Psicologia, Natal, v. 9, n. 2, p. 365-371, maio/ago. 2004.

SEVERO, Valdete Souto. A terceirização e os disfarces do discurso do direito do trabalho. In: FERRAREZE FILHO, Paulo; MATZENBACHER, Alexandre. Proteção do trabalhador: perspectivas pós-constitucionais. Rio de Janeiro: Lumen Juris, 2016, p. 147-170.

SOUTO MAIOR, Jorge Luiz. Curso de Direito do Trabalho: a relação de emprego. v. 2. São Paulo: LTr, 2008.

STRECK, Lênio Luiz. Jurisdição constitucional e decisão jurídica. 3. ed. São Paulo: Revista dos Tribunais, 2013.

VIANA, Márcio Túlio. Para entender a terceirização. São Paulo: LTr, 2015.

WEBER, Max. Economia e sociedade. Tradução Régis Barbosa. v. 1. 4. ed. Brasília: UnB, 2014.

Renato de Almeida Oliveira Muçouçah Professor na Faculdade Nacional de Direito da Universidade Federal do Rio de Janeiro (UFRJ). Bacharel em Direito pela Universidade Estadual Paulista (Unesp). Mestre e Doutor em Direito do Trabalho pela Faculdade de Direito da Universidade de São Paulo (USP). Pesquisador na Fundação de Amparo à Pesquisa do Estado de São Paulo (Fapesp) e na Capes. Pós-Doutor em Direito pela Universidade Federal do Maranhão (UFMA). E-mail: mucoucah@usp.br 